\title{
Near-Dead Cells to Special Tetraploidy to First Cells to Cancer Diagnostic Morphology: Unlikely Therapy-Gain from For-Profit Industrial Goliath
}

\author{
Kirsten H. Walen \\ CROMOS, Richmond, CA, USA \\ Email:kwalencromos@gmail.com
}

How to cite this paper: Walen, K.H. (2020) Near-Dead Cells to Special Tetraploidy to First Cells to Cancer Diagnostic Morphology: Unlikely Therapy-Gain from For-Profit Industrial Goliath. Journal of Cancer Therapy, 11, 410-432.

https://doi.org/10.4236/jct.2020.117036

Received: May 27, 2020

Accepted: July 19, 2020

Published: July 22, 2020

Copyright (อ 2020 by author(s) and Scientific Research Publishing Inc. This work is licensed under the Creative Commons Attribution International License (CC BY 4.0).

http://creativecommons.org/licenses/by/4.0/ (c) (i) Open Access

\begin{abstract}
The objective in this experimental article is to gain evidential proof of near-dead cells, (sick-cells in relapse tumor) responding with recovery growth from special $4 \mathrm{n}$, multi-chromatid chromosomes. Note, near-dead normal human cells with such converted chromosome structure gave rise to proliferative, fitness-gained, diploid first cells, which further gave rise to three different cell shape changed, recovery growth patterns. Previously, two cell shape changes had been recovered from same type normal human cells, transiently exposed to amino acid glutamine deficient growth medium with recovery growths also associated with presence of the special $4 \mathrm{n}$ cells. The $4 \mathrm{n}$ cell-division had been concluded to be a meiotic-like two-step division system to the fitness-gained diploid cells in numerous experiments. The main characteristics of this division system, was firstly whole genomes without polar oriented bent centromeres moving apart followed by much rarer simple fission division to two or three diploid cells, selectable for first cell proliferation. In general these $4 \mathrm{n}$ cells showed metaphase type rosette figures moving apart not in the normal spindle associated mitotic shape with centromeres polar-pointing with sloping arms. This sequence of events induced by glutamine-deficiency, was earlier shown to cause DNA breakage in metabolic studies however, the near-death condition was only assumed from normal fibro-blastic cell-sheet shrinkage. This was rectified by an RNA virus (Coxakie-B3), which virology known is a highly cell killing virus (4+ CPE on their scale). This virus replicates only in replicating cells, which led to recovery growths with progressive phenotypic cell-shape changes (spindle, polygonal and roundness cells), each intervened by "total" cell destruction. These three different growth patterns had morphologies, indistinguishably from today's cancer diagnostic
\end{abstract}


morphologies. "Mitotic" analyses of beginning growths for the three phenotypes revealed the special rosette figure separations from special $4 \mathrm{n}$ and higher ploidy level cells, and also total absence of spindle type mitoses. Tumorigenesis-relevant was centromere-puffing with premature chromatid separation, and chromatin compaction, a mechanism, that was suggested to protect the genome from damage (text). We suggest that the multi-chromatid polyploid cells with their genome reductive division system, can be a tractable in vitro model system for therapy information, when repeated from a cell-killing agent, producing virus-free recovery growths. Will it be enacted upon? Not likely with profit-greedy industrial Goliath in the helm of cancer research. But, a not for profit cancer organization, could change this appalling situation.

\section{Keywords}

Cytogenetics, Atavistic Activation, 4n-Division-Perpendicularity, Amalgamated Amitotic-Mitosis, Loss of Function Genetics, "Death" Recovery Cells, Driver Mutations, Tumor Parasitic Life

\section{Introduction}

\section{NOTE: "delicate" normal human cells compared to "tough" cancer cell lines}

This distinction between two cell sources in cancer research is generally not acknowledged. But it is acknowledged that normal cells work is time consuming, and therefore, avoided. True, they are proliferation negatively affected by "rough" handling, for example, they do not tolerate ongoing practice of centrifuged pellet suspension by vortex-use. And for example, WI-38 cells left 2 weeks in the same spent growth medium with detachment from the cultural surface, which was not an occurrence for the other L645 primary cells. Attachment to cultural surface is weak for primary cells compared to cancer cell lines (an adaptive feature?), and two of my colleagues gave-up from sudden death of the cells, but a third persisting with the most intrusive technique being exposure of cells to gene-transduction procedures with proliferative survival. Thus, herein where the data calls for verification of DSBs from phosphorylated histone protein, $\gamma \mathrm{H} 2 \mathrm{AX}$ nuclear foci and/or antibody-immune-fluorescence (FISH), there are no kits available, based on procedural tolerance of normal human cells. And, gain/loss of chromosomes is only available from karyotyping, another reason for rejection of such cell-use again seen as time consuming. Thus, whatever normal human cells can tell for potential tumorigenesis must stand on its own merit, and be challenged by other ways from for example, deducted consequences of such modeling, experimental possible in non-oncogenic human cell lines or in cancer cell lines. The encouraging situation for continuation in the use of normal cells, is that there is no other way to directly demonstrate cell changes leading to first cell development. 


\subsection{The Four Leading Contender Theories for Tumorigenesis Initiation}

Historically, the experimental phase did not start much before the discovery of carcinogens in early 1930s the inducers and promoters of tumors in animals, which a little later was transferred to cell cultures with direct access for cytogenetic studies. The since developed theories of cancer development, can be judged as to meaningfulness by its tumor induction in nude mice or in human tissue transplants in mice, which became reduced to 3-D growth in "sloppy" agar medium. Presently, the mutation theory (MT) is reigning in tumorigenesis, but without evidential proof for mutation-initiation of normal human cells where cancer starts [1] [2]. This latter requirement is equally missing in the other theories: 1) aneuploidy in initiation [3] [4], 2) embryological de-differentiation to "development gone awry" [5] [6], but contradicted by tetraploid cells associated with ovarian cancer metastasis [7], and 3) the proposition of budded cells from multinucleated cells (MNCs) [8]. In this latter regard, support for this idea from our works [9] [10] [11] with normal human cells, is wrong. Our budded cells from MNCs, disappointingly, showed only, max 3 - 4 doublings, which do not qualify for tumorigenesis initiation. All these suggested tumorigenesis initiations will stay hypothetic, until demonstrated in normal human cells, a hoped for realization in ongoing MT-based therapy, based on tumor driver capacity, published as an "idea" [1] [2].

\subsection{Previous Experimental Glutamine Deficiency Observations in Normal Human Cells}

Presently the goal/aim is to present evidential proof of near-death experienced cells, responding with recovery growths from cells having gained proliferative advantage, i.e., first cells, from a special division system expressed by tetraploid diplochromosomal cells (four-chromatid chromosomes) [12] [13] [14]. This remarkable discovery, not achieved in almost 200 years, is herein a target for clarifications of how the fitness-gain originated and how this diploid cell growth behaved in extended proliferation. This of course in relationship to the cancer literature, can bring cancer therapy into new considerations. Since preceding works were from the monitoring transiently exposed cells to deprivation of amino acid glutamine in the growth medium with cell shrinkage effect, a more visual show of cell killing was herein achieved by an RNA virus. These latter unusual findings are preceded summarily by the glutamine observations.

\subsection{Fitness-Gained Diploid Cells from Tetraploid 4-Chromatid Diplochromosomes}

These unique chromosomal structures were first accidentally observed in autoradiographic experiments, which showed high presence of both single and double recombination exchanges, indicative of being a response to DNA damage [15]. They were experimentally pursued, but not encountered before a sponta- 
neous appearance in a near-senescent population from our two normal human lung fibroblastic primary cell strains (L645, WI-38) [11] [16]. This sudden explosion of $4 \mathrm{n}$ diplochromosomal cells was confirmed in mouse near-senescent cells [17]. We reasoned that unstable broken telomere ends (from normal attrition), i.e., DNA damage, had caused a genomic doubling response, which we duplicated in young same cells from transient exposure to amino acid glutamine-deficiency in the growth medium [18] [19] (a rather fortuitous choice, see below), followed by recovery in complete medium with 2, 3 and 4 days harvests. These chamber slide harvests, fixed in 3:1 methyl-alcohol: acetic acid mixture, and G-banded from 2\% Giemsa, (2 min staining) showed division capacity of these uniquely structured chromosomal complements. Both diplo- and octoploid chromatid chromosomes were capable of divisions, which strangely was orderly in meiotic-like steps, firstly to $4 \mathrm{n} / 4 \mathrm{C}-8 \mathrm{n} / 8 \mathrm{C}$ cells followed by a rarer reductive, fission division to $2 n / 4 C-4 n / 4 C$ cells [12]. This latter publication, show rather detailed illustrations from photographs of $4 \mathrm{n}$ metaphase, rosette separations to countable 46 and 46 bichromatid chromosomal products (normal is to single chromatids). The chromosomes in the rosette genomes totally lacked bent centromere regions [20], and structural conformity for spindle determined poleward move, was absent. The bichromatid genomes less frequent divided by fission to either 2 - 3 or 4 cells, likely selected for fitness-gained propagation. This sequence of events is consistent with pre-cancers being diploid, and that $4 \mathrm{n}$ cell accumulated (see below) In pre-cancer cells centromere regions showed miss-orientations (not polar) and reduced stretching [20], interesting. The overall conclusion of amitotic divisions in cells with machinery for mitosis in the special $4 n$ cells, needs thinking. It was hinted at in discussions of endopoly-ploidy [21], but proof was evidentially shown from Drosophila cells [22]. The authors singled out tetraploid cells with amitotic genome reductive capacity, which led to cancer-like growth.

\subsection{Application to Tumorigenesis of the Special 4n-Division System}

It is of note, that the first recognized occurrence of $4 \mathrm{n}$ diplochromosomal cells was a spontaneous occurrence in normal cell populations with telomere critical attrition [11] [17] [23]. These broken DNA ends would seek immediate repair, which the special $4 \mathrm{n}$ cells showed from high frequency recombination events [15], and from single and double strand bridges between the amitotic, separated whole genomes. Bridges are famous for instigation of breakage-fusion-bridge (B-F-B) cycles in tumorigenesis [24] [25]. We judge the discovery of the special $4 \mathrm{n}$ cell-division system to fitness-gained first cells as outstanding, a hallmark discovery, because of the very first living proof in two centuries of cancer works. Even more so from a peculiar self-inflicted $90^{\circ}$ turn of the tetraploid nucleus before the meiotic-like division, producing proliferative first cells in a perpendicular orientation to the surrounding normal cells. The "skewed" division system had achieved freedom from proliferative contact inhibition, normally a fea- 
ture of normal cell types, forming a sheet of cells on the plastic surface. In pathological hyperplasia, the growth was measured to be in a $90^{\circ}$ position relative to the basal membrane [26]. This $4 \mathrm{n}$ peculiarity we see as a mechanism for the production of movable cells (below).

Furthermore, as mentioned, $4 \mathrm{n}$ cells accumulated in this hyperplasia, and was also a characteristic happening in other pre-neoplasia [27] [28]. Note, in Barrett's esophagus hyperplasia the accumulated $4 \mathrm{n}$ cells were isolated and put into cell culture medium (see small script description) in which they became "enriched" together with presence of a smaller cytometric peak of diploid cells [27]. The likely explanation is that the original $4 \mathrm{n}$ cells genome reduced to diploidy and, the diploid mitotic cells re-replicated to the $4 \mathrm{n}$ cells. In other words in this pre-cancer, these special $4 \mathrm{n}$ cells did not possess a fitness-gain, and the $2 \mathrm{n}$ cells, we suggest had been endowed (inherited from way of origin?) by the ability to create such $4 \mathrm{n}$ cells. This unique type of diploid-tetraploid cell cycling [27] is also known from sarcoma cell lines (see below). It cannot be pure chance that the oncogenic transformation process, associated with telomerase activation and immortality, in ulcerative colitis, showed change from diploid to cycling of tetraploid cells with asymmetric division products [28], adjusting around triploidy in continued propagation [17]. We showed the remarkable happening of 3-D tumor-like spheres, from polygonal shaped cells (originally from fibroblasts) in replicative senescence, which included the special 4n cells [13] [14]. In oral cancer this tetraploid cell division system showed multipolar (MP) rather disparate segregations from centrosome miss-behaviors, as for instance unequal divisions and "centrosomes" without centrioles [29], which hints of mitotic-amitosis problems, a study badly needing "conformation" from other cancer types. The connecting trait to $4 \mathrm{n}$-SDS cells (SDS = skewed division system) was daughter cells with new cytoskeletons in a skewed position relative to the original apical-basal axis of the $4 \mathrm{n}$ mother cell. In an earlier report on the wound healing programs, diplochromosomal cells were present, which was suggested to cause rarer associations between tissue damage and cancer development [30]. Again we remind of normal human cells' intolerance to experimental procedures [31], but tissue damage is likely to contain dead and near-dead cells with probability of recovery growth as discussed above for glutamine deficiency.

\subsection{Reasoning in the Suggested Activation of Genome Conserved, Atavistic Division System in Normal Human Cells}

The primitive origin of self-inflicted $90^{\circ}$ turned cell divisions relative to the cytoskeleton axis, is suggested to derive from unicellular organisms with moveable/swimming life-styles. These moving organisms have apical-basal body and nuclear orientation-symmetry, and when provoked by DNA damage the genome doubles for repair, which must be genome reduced to constitutional ploidy level [32]. And the " $4 \mathrm{n}$ " nucleus must turn $90^{\circ}$, perpendicular to the axial orientation, in order to produce mirror image daughter organisms. Some extant organisms 
today are showing this pre-division nuclear perpendicular turn, rather pertinent to organisms with exoskeletons [33] [34]. Thus, this $4 \mathrm{n}$ nucleus has genetics to achieve a $90^{\circ}$ turn relative to the cytoskeleton, and then divide, followed by "cytokinesis" of the organism. The similar self-inflicted perpendicular 4 n-nuclear turn in normal human cells suggest evolution conserved genetics in our genomes, activated by an atavistic happening. The fact that the $4 \mathrm{n}$-SDS division is genome reductive (as above) to diploidy, further suggests that genome damage is a trigger for this event. This proposal has strong support from the inherited cancer prototype, Blooms' syndrome in which a helicase, gene mutation (DNA unwinding protein), causes DNA damage (double strand breakage, DSB) with response to $4 \mathrm{n}$, diplochromosomal cells, notably with excessive repair, recombination frequencies compared to normal [15] [35] [36].

\subsection{An Introduction to Status Quo of Cancer Therapy}

Cancer therapy very recently got a boost from a totally new approach in immunotherapy, which earned the discoverers the 2018 Nobel Prize in medicine. Researchers Allison and Honjo found that a patient's T-cells could be manipulated in vitro by chemicals that taught these cells to recognize cancer cells as foreign with result of their death to cancer-free conditions. These manipulations have been especially successful for leukemia, but melanoma, prostate and lung cancers are not far behind. It has rejuvenated patient trust in immunotherapy, especially, because a "pint" of blood, only one week later returned to the body. Another break-through comes from CRISPR technology, which is rapidly advancing in "editing" of hereditary mutant genes, impressively shown on television for sickle cell "cure". However, this leaves cancer initiation from the magic, first cell, with potential for a cancerous process. Our theory of first cell origin from DDR in S-period, is called S-DDRT (S-period-DNA-damage-response-theory) [37]. This latter report showed that the cell cycle from one mitosis to the next became hours reduced [38] [39], which in itself is fitness producing.

\subsection{New Discoveries to Be Assimilated into Ongoing Chemo-Drug Therapy}

The fact of durable fitness-gained cells from such assumed happening (lacking molecular verification), is significant in itself, not having been attained in over 200 years of cancer behavioral studies. More so, because of normal human cell-use in these studies, where cancer originates. In vivo hyperplasia $4 \mathrm{n}$ cells in Barrett's esophagus, were proliferation arrested, but as said genome reduced to diploidy in cell culture medium, demonstrating heritable $4 \mathrm{n}-2 \mathrm{n}$ cycling and not propagative ability of the $4 \mathrm{n}$ cells [27]. In vitro these diploid cells showed 3-D spherical and disorganized multi-layered growths [13] [14], decidedly tumorigenesis characteristics. All together suggest therapy positivity from drugs against the genetics/epigenetics, determinants of the self-inflicted $90^{\circ}$ nuclear turn. The ongoing therapy against cancer appears not to be up-to-date emphasizing personalized genome-guided drug therapy, based on the belief that tumor 
revealed mutations drive tumorigenesis [1] [2]. This belief is based on an interpretation, and has no valid experimental proof. Since then the number of such mutations has grown to hundreds (called significantly mutated genes, SMGs), many of which awaiting drug screening, all lacking functional protein determination. Additionally, a recent re-evaluation of the drivers by the same laboratory, suggesting (idea) driver capacity of the mountain mutations [1] [2], concluded "no golden standard" for drivers [40] without more specifics, which can mean from none to positivity. Costly, wasteful works, are awaiting FDA approved anti-drug screenings, and worse is that Medicare is being asked to cover this cost. A cleaning-up in the questionable based genomic-guided therapy, strongly appears needed.

\subsection{Loss of Function Genetics}

Nowhere in the gain of function genetics of therapy today, is loss of function genetics discussed. This long known genomic condition from LOH and insufficiency, which also involves deletion mutations, would have gene functional effects. Adding the increasing findings of genome-wide uni-parental disomy (UPD), and the well-known "loss" of tumor suppressor genes, a discussion of how these genome changes have been incorporated into the genome-guided therapy, appears appropriate. On the horizon there is also likely coming acceptance of genetic inactivation from CNVs, which are molecular structures of the more familiar, visual HSRs and DMs [41] [42] [43]. These genomic structures would also need verifications of protein production, but then again, how would they be tested for functional activity, - tumor driver capacity? All likely without mutated protein production. The classical example of such a protein from gene-fusion in a translocation, has been in pro and con debate for driver capacity in some leukemia-types more than 30 years [44] [45], and is still not settled. To this should be added our recent discovery of numerous SMGs (about 25) located on borders to mapped potentially unstable A:T rich fragile sites [46]. These non-coding repetitive nucleotide regions, altogether 4 different types (fragile sites, micro-satellite regions, centromere heterochromatin and telomere repeats) have probability of becoming under replicated with deletion mutations, when S-period is significantly delayed for proper replication of this "late" replicating, satellite DNAs [47]. Furthermore, repair processes of the deletions were found to be unstable in both chemical and X-ray exposed normal human cells, which could mutational affect the coding genes located on their borders [48]. These well studied observations, we have claimed as an event when DNA damage is repaired in S-period. The desired proof from nuclear phosphorylated histone, $\gamma \mathrm{H} 2 \mathrm{AX}$ foci, has not been procedural worked-out for normal human cells (likely never to be done). As said above the tolerated cell changes by them-selves, have value, especially in this case of special $4 n$ cells being an only route to fitness-gained, likely, tumorigenic first cells. This achievement is in stark contrast to the proof-less fitness-gain advocated for the all-important SMGs in therapy. The further 4n-SDS attribute of producing first cells with new cytoskeletons in a 
perpendicular orientation relative to cells of origin, note, is a mechanism for cell movability. Also unexpected was first cell amitotic propagation from cell cycle reduced timings, a feature gained from the birth process of the 4n-SDS cells, fitness producing in itself. Note, to be considered is amitosis in cells with normal mitotic machinery.

\subsection{The Likelihood that Genes Determining the $90^{\circ}$ Cytoskeleton Turn Can Be Therapy Targeted}

To replace the dicey SMG-based therapy, there are numerous works citing or implicating cytoskeleton perpendicular move relative to the cell polarity axial orientation [49] [50] [51]. These works showed that the resultant cells in such orientations relative to surrounding cells had attained movability which has had special attention in metastasis [6] [7] [52] [53]. Contrary to the suggested EMT/MET derivation from de-differentiation to embryological similar cell axial changes [6], the most recent finding from ovarian cancer cells showed a skewed cytoskeleton in tetraploid cells undergoing division to genome reduced cells [7]. We speculate that this latter observation was from 4n-SDS cells. Movability of cells is also reflected in tissue distance between pre-cancers and malignant tumors [54] [55]. But directly therapy informative is a recent report on soft tissue sarcoma cell lines [56]. This important work found that some mitotic genes were over-expressed, and called it the CINSARC signature. These cancers lacked the common SMGs for therapy treatment, and showed fitness-gained aneuploid cells and, tetraploid cells, without proliferation, behaving "strikingly" motile and invasive. The authors speculated that a cytoskeleton change was responsible for the motility. They further reasoned that therapy targeting of determinants for the cytoskeleton change should reduce these tumors bad prognosis. They found that inhibition of some mitotic kinases indeed, "-drastically impair(ed) the CIN-SARC-cell invasive and migratory properties-". This remarkable, demonstration of markers (genes) determining the cytoskeleton turn, being susceptible to anti-marker gene treatments in therapy, is almost synonymous to our call for marker identity for the $4 \mathrm{n}-\mathrm{SDS}, 90^{\circ}$ nuclear turn. Thus, inhibition of mitotic kinases should be tried against these special tetraploid cells in vitro, and in progression studies [57] for therapy information.

\subsection{Tissue Micro-Environmental Stress: A Route to Tetraploidy, Division Capable to Genome Reduced Proliferative Cells}

An article, describing cell responses exposed to a micro-device, which mechanically exerted pressure on a single cell, measured in $\mu \mathrm{m}$ showed rather relevant cell happenings from HeLa cells [58]. The device could force a cell with basal-apical cell/nucleus polarity into a cell with a cytoskeleton axis changed, they had already hypothesized this development. The pressure on the cell could be increased-decreased which showing quantitative differences in types of mitotic segregated abnormalities, but preceded by a response to increased cell size, which in division produced "-drastic changes in size, shape, and symmetry of 
daughter cells-." For example, low pressure produced mostly two and tri-daughter results, whereas increased pressure changed to tri-and tetra-daughter divisions with "drastic" differences in size of segregated daughters. Since these responses were in the absence of multi-centrosome determined multipolar divisions, they called these anaphase lacking segregations, multi-daughter divisions. They write: “-multi-daughter division induced by confinement lead to viable daughter cells with increased chances of chromosomal abnormalities-". They concluded that "-cell shape (our marking) during mitosis may be a dominant factor in directing multi-daughter divisions-", and added that spherical shape is a response in "softer substrates". We interpret that the pressure having first accomplished an axial change of the cytoskeleton, the next was a response to polyploidization, photographically illustrated. This was then followed by "in-place", nuclear furrowing (amitosis) to size different, daughter cells, capable of division, shown in progression study [57], which is a step by step description of the special tetraploid cells (4n-SDS cells). Physical stress on cells being a potential inducer of tumorigenesis via polyploidy has not been considered before (to our knowledge), and is from the above a credible possibility.

\section{Visual Cell Death, Experimentally Induced by an RNA Virus}

The foregoing experimental studies were based on glutamine-deficiency producing assumed near-death cells with recovery ability, which in the present experiment leaves no doubt from a virus, affecting the highest degree (4+ CPE) on the scale of death in virology. In cancer therapy treatment from drugs this "total" cell death is the goal, but too often there is re-growth of relapse tumors, having been described originating from sick cells [59]. The tumorigenic important discovery was that the recovery growth was associated with polyploid reduction to lover ploidy cells, which were genome changed with resistance to original chemo-drug. From these now several studies [60] [61] [62] [63], the interpretation is that near-killing of cells can be associated with genome mutational damage, which is in the same vein of glutamine-deficiency producing DNA breakage [64] [65] [66]. In the present virus (Coxakie-B3) induced cell death, the special feature was virus replication only in cycling proliferating cells [67], which led to cycles of recovery growths intervened by $4+\mathrm{CPE}$. This murky medium from dead cells and debris was discarded before replacement by fresh growth medium. The virus causes a mild diarrhea, and has shown replication in cell cultures of different mammalian species, in rat cells with translocation chromosomes, i.e., genome damage [67].

\subsection{Methodology}

Since we are not virologists, but had some experience in cell infections from works with SV40 virus on normal human cells, we adopted this simplest of procedure to the Coxakie virus, and as previously used the two fibroblastic primary 
cell strains, WI-38 and L645. Thus, newly seeded T-25 flasks (Figure 1(A)) from about $4-5 \times 10^{3-4}$ cells with 6 days growth period, were washed with PBS, followed by $1 \mathrm{ml}$ inoculum distributed over the cell sheet and re-incubation at $37^{\circ} \mathrm{C}$. The inoculum was a 1 to 1 dilution from PBS of thawed cryopreserved stock virus, which initially, some 40 years earlier, contained $10^{6-7}$ infectious units, likely now rather reduced (not measured and not necessary for present purpose). After adsorption time, the cultures were again washed with PBS to remove un-adsorbed virus, followed by addition of growth medium with FBS (fetal bovine serum) reduced from normal growth medium $10 \%$ to $2 \%$.

\subsection{Specific Procedures and Live Phase Contrast Observations with Photography}

Phase contrast inspection was done daily, and at days 7 and 8 following infection the cell sheets had almost completely disappeared, but for a small network of interconnected "stringy" remains (Figure 1(C) \& Figure 1(E)). The present indication of cell death was verified by murky culture fluids possessing floating, much condensed cells and debris. The surface attached stringy remains were by my colleague virologists called $4+\mathrm{CPE}$, the endpoint in titration assays. But, the old culture fluids were discarded and fresh 10\% FBS medium added (fluid change), which at 8 - 10 days later had almost regrown confluent cell sheets. But of a thinner cell type (Figure 1(B)), spindle-like, compared to the original fibroblastic phenotype, and they showed a somewhat multilayered, disorganized growth pattern (Figure 1(B)). One flask from each strain was passaged (subculture) by standard trypsin/versene (EDTA-sol. from Gibco, =T/V) solution for cell surface detachment. The pellet was carefully resuspended in $2 \mathrm{ml}$ of medium, note, no vortex use, only gentle pipettings, followed by a 1:3 dilution in medium, which gave about $4-5 \times 10^{3-4}$ cells in $1 \mathrm{ml}$ seeding solutions (sub-culturing procedure) plus $9 \mathrm{ml}$ fresh 10\% FBS growth medium. These cultures regrew the spindle-like cells almost to confluency in 5 to 7 days, but shortly thereafter ( 3 - 4 days), the cultures were completely reduced to a network of $4+\mathrm{CPE}$, stringy remains and a cloudy medium from condensed, dead cells. Again this fluid was discarded and fresh growth medium added with re-incubation, but this time the regrown cell sheets were from polygonal shaped cells (Figure 1(D)), which in the WI-38 flasks was significantly sparser. For this culture, following subculture procedure, all cells were seeded into one flask and two chamber slides. Strain L645 showed strong polygonal cell growth, and sub-culturing was as earlier done with 4 chamber slides seeded with approximately 3 - 4 thousand polygonal cells. As before the polygonal cells grew back, but only a few small spots in the WI-38 flask. The L645 polygonal cells deteriorate from $4+\mathrm{CPE}$ in $3-4$ days. Fluid change was performed, which as before in $8-10$ days led to confluency from still another cell type, roundness cells (Figure 1(F)). Again new cultures were seeded, but mold contamination, rapidly showed presence in all these cultures. Since regrowth cells had been cryopreserved, attempts 

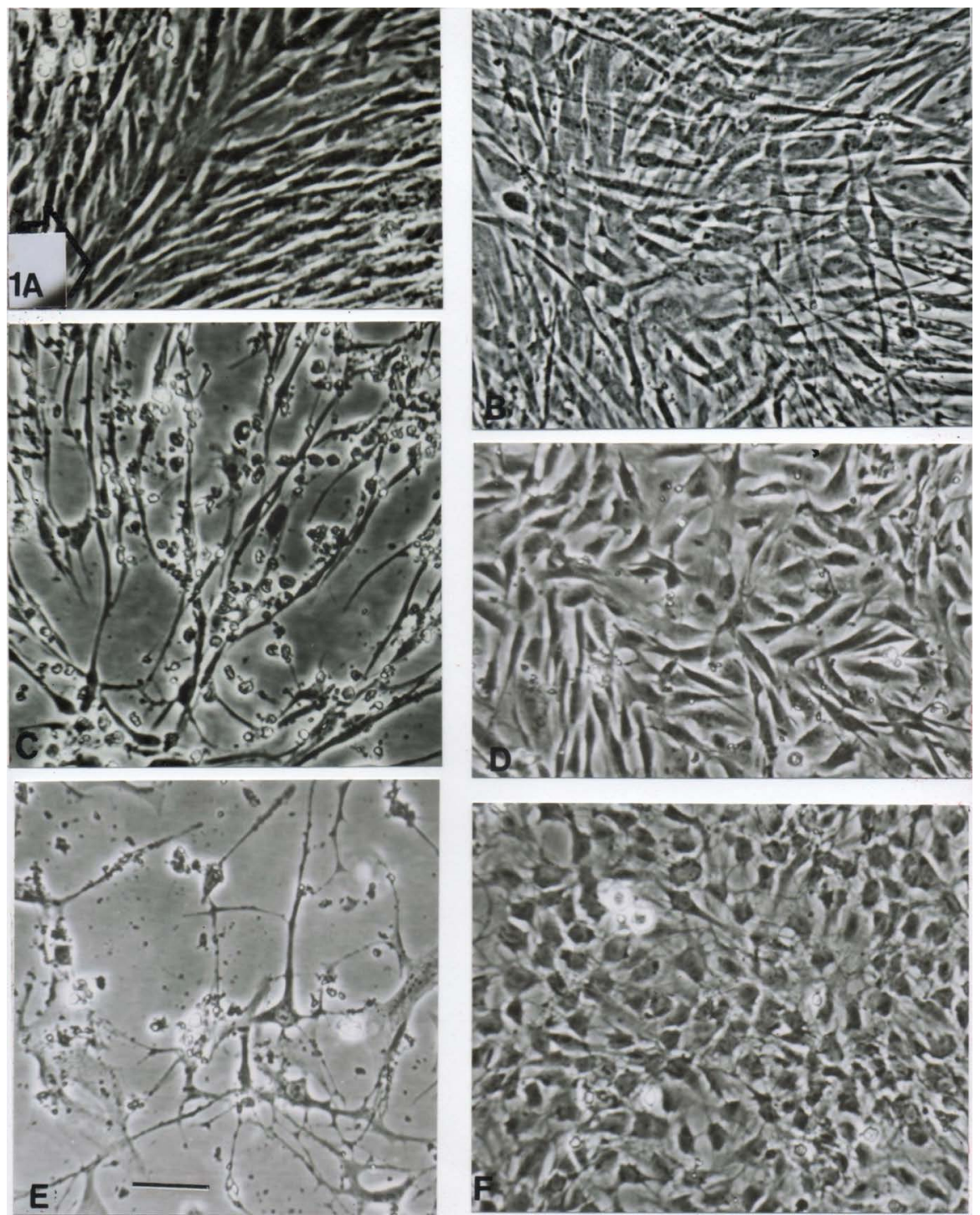

Figure 1. The Coxakie RNA virus caused cell killing and the different growth patterns of the recovery growths. (A) Normal human fibroblast growth pattern; (B) Spindle cell recovery growth; (C) Beginning cell death from fibroblasts; (D) Recovery polygonal cells. (E) A further development of fibroblastic cell death; (F) The last attained recovery growth from polygonal cells showing growth pattern from roundness cells. Note, the three mitotic or division products, and slightly to the right a polyploid nucleus. The scale bar is 25 $\mu \mathrm{m}$ in Figure $1(\mathrm{E})$.

to restart the strange progressive cell shape changes, but in vain, the cells in presence of virus had not tolerated the freezing. At this point, the 3:1 (alcohol: acetic acid) fixed chamber slides were an asset, but they had not been included in the beginning from fibroblast cells to spindle cells, and a new virus ampoule was used in repetition of previous procedures. But this time only from L645 cells in flask and on chamber slides. This however, did not go far only to some regrowth of polygonal cells when mold became present (a wet incubator for chamber slide, not good for flask cultures). The good part though, was that the successive cell shape changes were partly reproduced. 

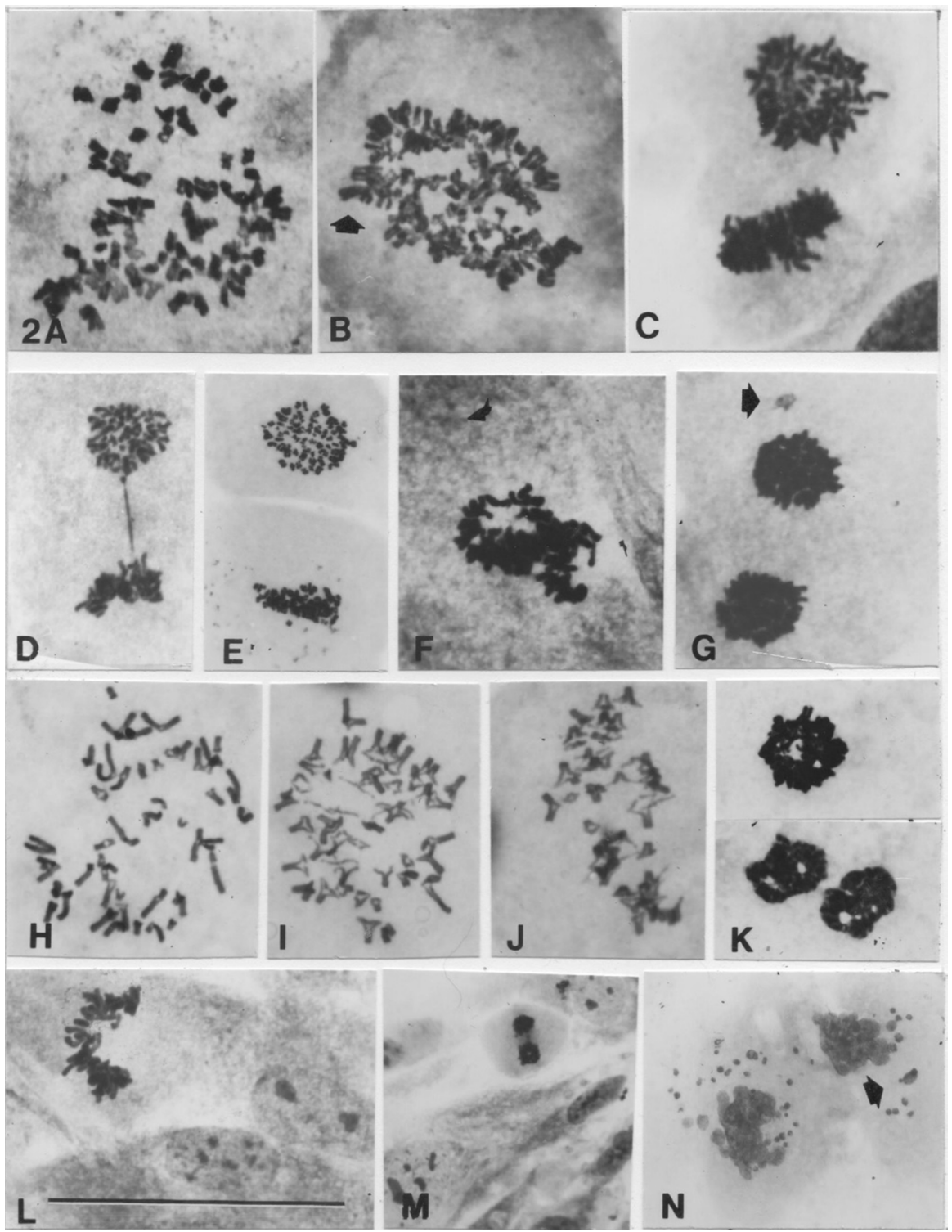

Figure 2. (A) A 4n diplochromosomal cell; (B) An 8n diplochromosomal cell; (C) 8n division products with two-plane views; (D) \& (E) $4 \mathrm{n}$ division products in two plane views; (F) Metaphase division products in 2-plane views; (G) $4 \mathrm{n}$ telophase chromatin compacted division products showing a centrosome with two centrioles (arrow); (H)-(J) 46 chromosomal cells showing centromere puffing and premature chromatid separation (see [13] [16]); (K) Chromatin compacted metaphase figure and a cell with compacted genomes, telophase segregated; (L) (M) Axial perpendicular divisions, note, orientation relative to interphase nuclei; $(\mathrm{N})$ Non-surviving division products surrounded by micro-nuclei. The scale bar is $120 \mu \mathrm{m}$ in Figure 2(L).

\subsection{Chamber Slide Observations and Discussion}

The fixed slides without any additional treatments were carefully stained with $2 \%$ Giemsa solution (1-1/2 - $2 \mathrm{~min}$ ), which is probably the best stain for chromosomal structure. "Mitotic" analyses of dividing cells are illustrated on composite plate, Figure 2, where selected types of abnormalities are shown, because some 30 plates of more general "mitotic" types are already published in this 
same journal. The selected types were present in all three beginning growths. One feature in all these different types is consistently present, that of a metaphase structure without bent centromere regions pointing poleward, as is normal for normal mitosis. Figure 2(A) \& Figure 2(B) are from 4 and 8 chromatid chromosomal genomes. The special $90^{\circ}$ turn of $4 \mathrm{n}$ nuclei, was a consistent feature in all three recovery growths, but also the $2 \mathrm{n}$ cells show such perpendicularity to the cells axis. Overall the level of mitotic catastrophe [68], decreased markedly from proliferative cells giving rise to spindle cell growth, which after that became absent in beginning growths to polygonal and roundness cell sheets. An attempt of a classification of the different abnormalities, did not work-out for data from two experiments, possibly due to use of un-synchronized fibroblast cultures to begin with.

The singled out special divisions, in particular is one observed earlier, but not understood to be different from chromosomal condensation, the so-called, chromatin compaction remodeling (Figure 2(G) \& Figure 2(K)) [69]. This feature importantly, was suggested to be a survival response against genomic damage, here likely from death signals. The other two types in Figure 2, were premature centromere/chromatid separations (PCS \& PSC) (Figures 2(H)-(J)), at one time, sought experimentally in early colon tumorigenesis [70], and 2-plane views of telophases. One division product was in polar view the other inside view (Figures 2(C)-(F) \& Figure 2(L)), which implicates a perpendicular turn during the division sequence. In the glutamine experiments early prophase cells, divided directly to telo-interphase cells which were in such 2-plane views relative to each other [16]. The benefit in tumorigenesis is a speculated gain of cell movability. Bridges between telophase figures with possibility of B-F-B cycles as seen were also present. The intriguing observation to us was chromatin compaction with possible function of protecting the genome from damage, here viral caused death, which brings to mind a published picture showing two cells with compacted telophase nuclei from breast cancer cells, but claimed to be over-sized centrosomes (incredible: was it cancer pathology today?) [71]. These nuclei, were "sticking out as soar thumbs" in the breast tumor, meaning that cancer cells also know how to protect against genomic damage.

\subsection{Why Is Descriptive, Tissue Morphology Used in Cancer Diagnosis and Prognosis in Today's Atmosphere of Mutation Caused Tumorigenesis?}

It is paradoxical that cancer diagnosis and prognosis are done from descriptive criteria when the investigative focus is on mutations ("the cancer genome") as initiation cause and evolution to the cancerous phenotype [72]. And even more confounding is the fact that these descriptive morphologies were developed some 200 years ago [73], and have shown only small, detailing changes. No wonder there is confusion even among the leading cancer scientists [74]. This ongoing diagnostic/prognostic descriptive pathology, has similar features to the present near-death recovery growth-morphologies, which as in cancer pathology 
were developments more and more distant from "tissue" of origin (widening distance from fibroblastic growth pattern). This similarity was also shown by the in vitro individual cells being increasingly less sensitive to death-signals, and with the familiar nuclear hyperchromatic phenotype, likely from discussed chromatin compaction. These in vitro growth pattern morphologies (Figure 1) have also shown the tumor characteristics of 3-D, tumor-like spheres from polygonal cells and disarranged multilayered growths from tetraploid fibroblastic cells [13] [14]. Von Hansemann (200 years ago) in cancer pathology added cell shape changes as a progressive feature to roundness of cells [73], argued to mediate tumor independent living from host forces, today equated to speciation of individual tumors [3] [4]. The question however, is whether the roundness recovery growth had under-gone oncogenic transformation with gained telomerase immortality (above)? This greatly neglected cancer-deciding issue in cancer research [75], is not understandable, and shrieks why? If the interest exists for a tractable model system to investigate oncogenic transformation, we believe that use of a near-death cell killing agent with use of present protocol, will repeat the different growth pattern-changes, now available for molecular studies. This would also provide answer to mutational changes and aneuploidy possibly involving SMGs. As mentioned, the chemo-drug relapse tumors were found to go through a genome doubling capable with reductive division to genetic changed lower level ploidy cells [60] [61] [62] [63], which was interpreted to also involve $4 \mathrm{n}$-SDS cells' inherited ability of meiotic-like reduction division. A latest report on this issue point-out that the basic of a polyploid shift is genome repair and that this condition is "undervalued" in relapse and in therapy [76]. This increasing attention to genome repair activity in tumorigenesis, was recently acted-upon by the "drugging" of DDR [77], which had positive results from one drugging-agent, and that more was in the pipeline, awaiting FDA approval. This promising result together with anti-kinases toward the 4n-SDS system, could perhaps lead to vaccine information, the Achilles heel of cancer disease.

\section{The First Cell}

Cancer being a somatic cell, genetic/epigenetic disease, lately had up-date for the MT as the reigning theory from mathematic modeling, but again it was not applicable to initiation of tumorigenesis, claimed, but not cell evidentially supported [78] [79]. One report showed reaction to the MT by considering no direct mutational occurrence [80] to which we add that they are consequences from cellular mechanistic events [14]. At that stage of a beginning, other cancer gurus have long claimed the need for a mechanism that can produce "first" cells, endowed with a proliferative advantage [81], which has many suggestions, but no show, accept our special $4 \mathrm{n}$ cells [14]. In tumorigenesis the first cells were early found to proliferate clonally (Cairns) [82] [83], but has had little to no attention. As mentioned, we have advocated genomic damage as a core event for the machinery that cause first cells from special $4 \mathrm{n}$ cells, which in "todays" articles with 
nitty-gritty molecular technology are found to occur also from nongenotoxic therapies. MTOR was a sensor of DNA damage, evidentially shown by phosphorylated histone $\gamma \mathrm{H} 2 \mathrm{AX}$ foci, further revealed as nucleotide mutations [84]. This unexpected mutational source, suggested to generate genetic diversity to multi-clonal tumors. This interpretation is supporting of our theory, suggesting genome damage activation of $4 \mathrm{n}$ and higher ploidy cells, which with asymmetric cell division (tougher cells after oncogenic transformation), would explain the chromosomal land-scape in tumorigenesis.

Raza [83] as a seasoned oncologist in her book, The First Cell, in contrast, sees cancer from the patient's point of view, a devastating disease, badly needing improvements in therapy. As the nitty-gritty article [84] points out there are more failures than success in the "ongoing chase for control of this disease" [83], a losing battle, she concludes. She adamantly proposes a shift to unlock the secret(s) of how first cells arise for beginning/initiation of tumorigenesis, which is a far different approach from the ongoing chases for more SMG identifications, costing billions. This chase is because, Big Pharma-industry, promises drugs to combat these assumed tumor driver SMGs, not evidentially proven, it was [1] [2] and is only an idea. This uncertainty and the erratic results from SMG-based genome-guided therapy, have led to a commentary article, asking: "Is genome-guided cancer therapy hyped" [71]. A graph in this article from 2006 to 2018 shows \% of patients eligible for genome-guided therapy, and those "expected to benefit from drug". There is a consistent near 10\% gap between the two over these 12 years, demonstrating "unbelievable" slowness in drug development. A fact Raza [83] is in full agreement with, saying that drugs she used in the $1970^{\text {th }}$ are the same today, and asks why? She also points out that these old drugs have bad, painful side-effects, some patients described, worse than the cancer itself, and in the end to no avail, certainly not worthy of the sky-high therapy pricings, ruining families (avr. 100,000.00 dollars). She says further: "-The goal in cancer is not to understand it at its densest molecular level, but to learn how to control it-". And most important: "-The gaping disconnect between knowledge about cancer biology and the capacity to use this knowledge to benefit the patient is enormous-". We, the cancer investigative scientists, must stop our ponderings for clever "cancer" answers, and focus on it being a disastrous disease, which can be controlled if we unlock the secrets to the origin(s) of The First Cells.

\section{Conclusions}

One tractable model system for tumorigenesis, first cell beginning, is available for in vitro further molecular explorations. The basic event, note, in normal human cells (not cancer cell lines), was cell proliferative recovery from near-death signals, induced by a high cell killing RNA virus. Rarer "sick cells" responded with doubling of the genome, we previously had described from amino acid glutamine deficiency, giving rise to a special type of tetraploidy, 4-chromatid 
diplochromosomal cells. Such $4 \mathrm{n}$ cells are endowed with four unique attributes: genome reductive, meiotic-like division system, a capacity to place progeny first cells in a perpendicular orientation from a cytoskeleton $90^{\circ}$ turn, first cell propagation with a proliferative advantage (fitness-gain), and this propagation being from an adapted amitotic-mitotic division system (from numerous photographic illustrations). The cytoskeleton perpendicular change, facilitated gain of cell movability, and fitness gain included reduced cell cycle time.

The fact that glutamine-deficiency produced genomic damage, and special tetraploid cells were a response in many ways, was similar to chemo-drug killing with response of polyploid cells giving rise to genome reduced relapse tumor cells, now showing genetic resistance to original chemo-drug. In other words, tumor cells have the capacity of genome reductive divisions, which is interpreted to be an inheritance from the first establishment in $4 \mathrm{n}$, diplochromosomal cells. Our suggested genome damage from glutamine-deficiency was specific for the S-period, modeled after the laboratory showing of X-ray and chemical mutational effects from S-period replication stress. Specifically, the late replicating, satellite DNAs showed repair instability from delayed replication forks in S. Indeed, these non-cancer discovered data are rather pertinent for genome damage so increasingly having a say, even in therapy, discussing MTOR stress inducing mutations. A conclusion was also with literature support that cell cycle delay is one requirement for mitotic slippage process, which gave rise to the important, unique $4 \mathrm{n}$ cells.

The ultimate proof of near-dead cells capable of recovery in the present experiments with a highly efficient cell killing RNA virus demonstrating progressive, different types of recovery growths from cell phenotypic different growth patterns, was totally unexpected, never before shown experimentally in tumorigenesis. The start was from normal fibroblastic, striated growth pattern, to spindle cells, next to polygonal and last to roundness cells patterns. The conclusion was that these different phenotypic cell patterns strongly mimicked tumorigenesis pathological morphologies, being used today in diagnosis and prognosis. This semblance had earlier been observed from polygonal cell in 3-D tumor-like spheres having started out from fibroblastic, special $4 \mathrm{n}$ cells, having gone through a senescence period. From "mitotic" analyses of beginning recovery growths, it was concluded that $4 \mathrm{n}-8 \mathrm{n}$-multi-chromatid chromosomes with genome reductive divisions started the three cell phenotypic recovery growths. Two other types of divisions with likely tumorigenesis application was chromatin compacted genomes, believed to be a genome damage, defense mechanism, and premature centromere and chromatid separations, mentioned in the cancer literature. These virus results strongly argue for repeat of present result from a cell killing agent, producing virus-free recovery growths that can be further explored, especially in regard to molecular changes that could be therapy informative. Thus, the overall conclusion is a tractable model system for multiple exploration of tumorigenesis: the changes normal cells undergo to end-up as First Cells, their oncogenic transfor- 
mation, the Cancer deciding step-into progression with its evolutionary developments perhaps to movable metastasis cells. This model system depends in part on whether the roundness cell pattern is oncogenic transformed, positive for telomerase gene activation. Will this new model be enacted upon? Not likely in the present atmosphere of for-profit cancer-rulings, a bottom-less greedy, colossal industry, such described in a couple of science articles.

\section{Cancer: Governed by Profit-Greedy Goliath and Politics?}

The fact that cancer originates from one genome changed cell with beginning clonal development, has been known for over 40 years, has this led to a meaningful, centered investigation on how is this cancer deciding cell originated? No, lots of hypotheses, but no real evidence, before our model, Why? One answer is: since cancer disease became for profit in the $1970^{\text {th }}$, there is since a colossal world-wide industry built-up to meet all ongoing equipment requirements a techno-logical laboratory must operate from. This industry has now its own momentum for continuation of business as usual, an unshakable giant, greedy Goliath. Today we see the same competitive rush from scientists and companies to be the first for lucrative patent-rights in the many aspects of controlling COVID-19. These scientists, happy from dollar-Goddess, show indifference to their science-callings, participating in business as usual, controlled by Goliath. My colleagues in cell biology have repeatedly complained of grant applications not being funded, unless there is claimed genome sequencing to support the prospective data. If true, it is a forced way into support of Goliath, and note, it secures new science recruits with robotic-technology at their fingertips. The word in the street is that the goal in the ongoing molecular focus in cancer research, is development of a pill that will make cancer a liveable chronic disease, cynically, translated to consistency in treatment profits, now on average over 100,000 dollars, ruining families. Presidents after presidents promise reductions in health care-costs in Nation addresses, and quickly, a standing ovation across the aisles erupts, but so far to no avail. Is it that the government is ineffective or is it, budget-dependent on ruling Goliath? Greed cannot be stopped. But, a private not-for-profit organization could change this mess to "cancer-disease" for therapy and vaccine development.

\section{Flow Chart of Selected Literature}

1) Therapy based on an "Idea" of tumor driver capacity from SMGs: [1] [2] [40] [78] [79] [80].

2) Glutamine-deficiency (GD) being genome damaging: [64] [65] [66].

3) Normal human cells exposed to GD affects creation of special tetraploid cells: [12] [13] [14] [16].

3) Tetra-polyploid response to genomic damage: [8] [17] [18] [19] [21] [22] [23] [26] [27] [30] [46] [56]-[63] [76].

4) S-period genomic damage repair, a replication stress affecting dele- 
tion-repair instability of satellite DNAs with consequence of mutations in bordering coding genes: [46] [47] [48].

5) GD caused damage repair in S-period with consequence of time delay (slowed/stalled replication forks), affects the response of special $4 \mathrm{n}$ cells through mitotic slippage process: [14] [16] [19] [30] [37] [46] [47] [48].

6) The $4 \mathrm{n}$ cells, being 4-chromatid diplochromosomes, born with innate, two unique division features: meiotic-like reduction division producing, $2 n$-progeny First Cells endowed with fitness-gain, and secondly in the $4 \mathrm{n}$ reductive division, mother nucleus turns $90^{\circ}$ to the axial cytoskeleton affecting new skewed oriented cytoskeletons in the fitness-gained first cells. They have gained freedom from proliferative contact inhibition: [11] [12] [13] [14] [16] [18] [27] [30].

7) $4 \mathrm{n}$ nuclear $90^{\circ}$ turn followed by division, is a mechanism for cell motility: [46] [50] [51] [56].

8) Six above was delineated to primitive organisms with axial cytoskeletons for swimming, they must perform a $90^{\circ}$ nuclear turn before division. This suggests an atavistic reawakening of evolutionary conserved genetics for 6) in our genomes: [19] [32] [33] [34].

\section{Acknowledgements}

I am deeply thankful to Kathleen Olival, for always readiness to fix computer problems and help with manuscript requirements.

\section{Conflicts of Interest}

The author declares no conflicts of interest regarding the publication of this paper.

\section{References}

[1] Wood, L.D., Parsons, D.W., Jones, S., Lin, J., Sjoblom, T., Leary, R.J., et al. (2007) The Genomic Landscapes of Human Breast and Colorectal Cancer. Science, 318, 1108-1113. https://doi.org/10.1126/science. 1145720

[2] Bozic, I., Antal, T., Ohtsuki, H., Carter, H., Kim, D., Chen, S., Karchin, R., et al. (2010) Accumulation of Driver and Passenger Mutations during Tumor Progression. Proceedings of the National Academy of Sciences of the United States of America, 107, 18545-18550. https://doi.org/10.1073/pnas.1010978107

[3] Duesberg, P., Madrioli, D., McCormack, A. and Nicholson, J.M. (2011) Is Carcinogenesis a Form of Speciation? Cell Cycle, 10, 2100-2114.

https://doi.org/10.4161/cc.10.13.16352

[4] Vincent, M.D. (2009) The Animal Within: Carcinogenesis and Clonal Evolution of Cancer Cells Are Speciation Events Sensu Stricto. Evolution, 64, 1173-1183. https://doi.org/10.1111/j.1558-5646.2009.00942.x

[5] Sonnenschein, C. and Soto, A.M. (2013) The Aging of the 2000 and 2011 Hallmarks of Cancer Reviews: A Critique. Journal of Biosciences, 38, 651-663. https://doi.org/10.1007/s12038-013-9335-6

[6] Kalluri, R. and Weinberg, R.A. (2009) The Basics of Epithelial-Mesenchymal Transition. The Journal of Clinical Investigation, 119, 1420-1428. https://doi.org/10.1172/JCI39104 
[7] Rohnalter, V., Roth, K., Finkernagel, F., Adhikary, T., Obert, J., Dorzweiler, K., et al. (2015) A Multi-Stage Process Including, Transient Polyploidization and EMT Precedes the Emergence of Chemoresistant Ovarian Carcinoma Cells with a Dedifferentiated and Pro-Inflammatory Secretory Phenotype. Oncotarget, 6, 40005-40025. https://doi.org/10.18632/oncotarget.5552

[8] Liu, J. (2019) The "Life Code": A Theory That Unifies the Human Life Cycle and the Origin of Human Tumors. Seminars in Cancer Biology, 60, 380-397.

https://doi.org/10.1016/j.semcancer.2019.09.005

[9] Walen, K.H. (2004) Spontaneous Cell Transformation: Karyoplasts Derived from Multi-Nucleated Cells Produce New Cell Growth in Senescent, Human Epithelial Cell Cultures. In Vitro Cellular \& Developmental Biology: Animal, 40, 150-158. https://doi.org/10.1290/1543-706X(2004)40<150:SCTKDF>2.0.CO;2

[10] Walen, K.H. (2005) Budded Karyoplasts from Multinucleated Fibroblast Cells Contain Centrosomes and Change Their Morphology to Mitotic Cells. Cell Biology International, 29, 1057-1065. https://doi.org/10.1016/j.cellbi.2005.10.016

[11] Walen, K.H. (2006) Human Diploid Fibroblast Cells in Senescence: Cycling from Polyploidy to Mitotic Cells. In Vitro Cellular \& Developmental Biology: Animal, 42, 216-224. https://doi.org/10.1290/0603019.1

[12] Walen, K.H. (2007) Bipolar Genome Reductional Division of Human Near-Senescent, Polyploid Fibroblast Cells. Cancer Genetics and Cytogenetics, 173, 43-50. https://doi.org/10.1016/j.cancergencyto.2006.09.013

[13] Walen, K.H. (2011) Normal Human Cell Conversion to 3-D Cancer-Like Growth: Genome Damage, Endopolyploidy, Senescence Escape, and Cell Polarity Change/Loss. Journal of Cancer Therapy, 2, 181-189. https://doi.org/10.4236/jct.2011.22023

[14] Walen, K.H. (2013) Normal Human Cells Acquiring Proliferative Advantage to Hyperplasia-Like Growth-Morphology: Aberrant Progeny Cells Associated with Endopolyploid and Haploid Divisions. Cancer and Clinical Oncology, 2, 19-33. https://doi.org/10.5539/cco.v2n2p19

[15] Walen, K.H. (1965) Spatial Relationships in the Replication of Chromosomal DNA. Genetics, 51, 915-929.

[16] Walen, K.H. (2012) Genome Reversion Process of Endopolyploidy Confers Chromosome Instability on Descendent Diploid Cells. Cell Biology International, 36, 137-145. https://doi.org/10.1042/CBI20110052

[17] Davoli, T. and de Lange, T. (2011) The Causes and Consequences of Polyploidy in Normal Development and Cancer. Annual Review of Cell and Developmental Biology, 27, 585-610. https://doi.org/10.1146/annurev-cellbio-092910-154234

[18] Walen, K.H. (2013) Senescence Arrest of Endopolyploid Cells Renders Senescence into One Mechanism for Positive Tumorigenesis. In: Hayat, M.A., Ed., Tumor Dormancy and Cellular Quiescence and Senescence, Vol. 1, Springer, Dordrecht, 215-226. https://doi.org/10.1007/978-94-007-5958-9 18

[19] Walen, K.H. (2018) Genomic Instability in Cancer I: DNA-Repair Triggering Primitive Hereditary 4n-Skewed, Amitotic Division-System, the Culprit in EMT/MET/ Metaplasia Cancer Concept. Journal of Cancer Therapy, 9, 974-997. https://doi.org/10.4236/jct.2018.912081

[20] Draviam, V.M., Shapiro, I., Aldridge, B. and Sorger, P.K. (2006) Missorientation and Reduced Stretching of Aligned Sister Kinetochores Promote Chromosome Missegregation in EB1- or APC-Depleted Cells. The EMBO Journal, 25, 2814-2827. https://doi.org/10.1038/sj.emboj.7601168

[21] Fox, D.T. and Duronio, R.J. (2013) Endoreplication and Polyploidy: Insight into 
Development and Disease. Development, 140, 3-12. https://doi.org/10.1242/dev.080531

[22] Lucchetta, E.M. and Ohlstein, B. (2017) Amitosis of Polyploid Cells Regenerates Functional Stem Cells in Drosophila Intestine. Cell Stem Cell, 20, 609-620. https://doi.org/10.1016/j.stem.2017.02.012

[23] Davoli, T. and de Lange, T. (2012) Telomere-Driven Tetraploidization Occurs in Human Cells Undergoing Crisis and Promotes Transformation of Mouse Cells. Cancer Cell, 21, 765-776. https://doi.org/10.1016/j.ccr.2012.03.044

[24] Gisselsson, D. and Egnell, R. (2017) Cancer-An Insurgence of Clones. Trends in Cancer, 3, 73-75. https://doi.org/10.1016/j.trecan.2016.11.010

[25] Wong, D.J., Paulson, T.G., Prevo, L.J., Galipeau, P.C., Longton, G., et al. (2001) p16 ${ }^{\text {INK4a }}$ Lesions Are Common, Early Abnormalities That Undergo Clonal Expansion in Barrett's Metaplastic Epithelium. Cancer Research, 61, 8284-8289.

[26] Dikovskaya, D., Schiffmann, D., Newton, I.P., Oakley, A., Kroboth, K., Sansom, O., et al. (2007) Loss of APC Induces Polyploidy as a Result of a Combination of Defects in Mitosis and Apoptosis. Journal of Cell Biology, 176, 183-195.

https://doi.org/10.1083/jcb.200610099

[27] Barrett, M.T., Pritchard, D., Palanca-Wessels, C., Anderson, J., Reid, B.J. and Rabinovitch, P.S. (2003) Molecular Phenotype of Spontaneously Arising 4N ( $\mathrm{G}_{2}$-Tetraploid) Intermediates of Neoplastic Progression in Barrett's Esophagus. Cancer Research, 63, 4211-4217.

[28] Steinbeck, R.G. (2004) Dysplasia in View of the Cell Cycle. European Journal of Histochemistry, 84, 203-211.

[29] Saunders, W.S., Shuster, M., Huang, X., Gharaibe, B., Enyenihi, A.H., Petersen, J. and Gollin, S.M. (2000) Chromosomal Instability and Cytoskeleton Defects in Oral Cancer. Proceedings of the National Academy of Sciences of the United States of America, 97, 303-308. https://doi.org/10.1073/pnas.97.1.303

[30] Walen, K.H. (2015) Wound Healing Is a First Response in a Cancerous Pathway: Hyperplasia Developments to 4n Cell Cycling in Dysplasia Linked to Rb-Inactivation. Journal of Cancer Therapy, 6, 906-916. https://doi.org/10.4236/jct.2015.610099

[31] Weaver, B.A. and Cleveland, D.W. (2006) Does Aneuploidy Cause Cancer? Current Opinion in Cell Biology, 18, 658-667. https://doi.org/10.1016/j.ceb.2006.10.002

[32] Hurst, L.D. and Nurse, P. (1991) A Note on the Evolution of Meiosis. Journal of Theoretical Biology, 150, 561-563. https://doi.org/10.1016/S0022-5193(05)80447-3

[33] Buchsbaum, R. (1951) Animals without Backbones, Vol. 1. Penguin Books, London.

[34] Grell, K.G. and Ruthmann, A. (1964) Uber die Karyologie des Radiolars Aulachanta scolymantha und Feinstruktur seiner Chromosomen. Chromosoma, 15, 185-211. https://doi.org/10.1007/BF00285729

[35] Kuhn, E.M. and Therman, E. (1986) Cytogenetics of Bloom's Syndrome. Cancer Genetics and Cytogenetics, 22, 1-18. https://doi.org/10.1016/0165-4608(86)90132-9

[36] Bachrati, C.Z. and Hickson, I.D. (2003) RecQ Helicases Suppressors of Tumorigenesis and Premature Aging. Biochemical Journal, 374, 577-606. https://doi.org/10.1042/bj20030491

[37] Walen, K.H. (2017) Mitotic Slippage Process Concealed Cancer-Sought Chromosome Instability Mechanism (S-CIN). Journal of Cancer Therapy, 8, 608-623. https://doi.org/10.4236/jct.2017.86052

[38] Walen, K.H. and Brown, S.W. (1962) Chromosomes in a Marsupial (Potororous tridactylis) Tissue Culture. Nature, 194, 406-408. https://doi.org/10.1038/194406a0 
[39] Brenner, S., Branch, A., Meredith, S. and Berns, M.W. (1977) The Absence of Centrioles from Spindle Poles of Rat Kangaroo (PtK-2) Cells. Journal of Cell Biology, 72, 368-379. https://doi.org/10.1083/jcb.72.2.368

[40] Tokheim, C.J., Papadopoulis, N., Kinzler, K.W., Vogelstein, B. and Karchin, R. (2016) Evaluating the Evaluation of Cancer Driver Genes. Proceedings of the National Academy of Sciences of the United States of America, 113, 14330-14335. https://doi.org/10.1073/pnas.1616440113

[41] Storlazzi, C.T., Lonoce, A., Guastadisegni, M.C., Trombetta, D., et al. (2010) Gene Amplification as Double Minutes or Homogeneously Staining Regions in Solid Tumors: Origin and Structure. Genome Research, 20, 1198-1206. https://doi.org/10.1101/gr.106252.110

[42] Davoli, T., Uno, H., Wooten, E.C. and Elledge, S.J. (2017) Tumor Aneuploidy Correlates with Markers of Immune Evasion and with Reduced Response to Immunotherapy. Science, 355, eaaf8399. https://doi.org/10.1126/science.aaf8399

[43] Beroukhlim, R., Mermel, C.H., Porter, D., Wei, G., Raychaudhuri, S., Donovan, J., Barretina, J., Boehm, J.S., Bobson, J., et al. (2010) The Landscape of Somatic Copy Number Alterations across Human Cancers. Nature, 463, 899-905. https://doi.org/10.1038/nature08822

[44] Heim, S. and Mitelman, F. (1995) Cancer Cytogenetics: Chromosomal and Molecular Genetic Aberrations of Tumor Cells. 2nd Edition, Wiley-Liss, Inc., New York.

[45] Mitelman, F. (1988) Catalog of Chromosome Aberrations in Cancer. Alan Liss, Inc., New York.

[46] Walen, K.H. (2019) Genomic Instability in Cancer II: 4N-Skewed (90 $)$ Reductive Division via Fragile Sites to Fitness Increase for Solid and Hematological Cancer Beginnings. Journal of Cancer Therapy, 19, 537-564. https://doi.org/10.4236/jct.2019.107045

[47] Durkin, S.G. and Glover, T.W. (2007) Chromosome Fragile Sites. Annual Review of Genetics, 41, 169-192. https://doi.org/10.1146/annurev.genet.41.042007.165900

[48] Durkin, S.G., Ragland, R.L., Artl, M.F., Mulle, J.G., Warren, S.T. and Glover, T.W. (2008) Replication Stress Induces Tumor-Like Microdeletions in FHIT/FRA3B. Proceedings of the National Academy of Sciences of the United States of America, 105, 246-251. https://doi.org/10.1073/pnas.0708097105

[49] Royer, C. and Lu, X. (2011) Epithelial Cell Polarity: A Major Gatekeeper against Cancer? Cell Death \& Differentiation, 18, 1470-1477.

https://doi.org/10.1038/cdd.2011.60

[50] Etienne-Manneville, S. and Hall, A. (2003) Cdc42 Regulates GSK-3 $\beta$ and Adenomatous Polyposis Coli to Control Cell Polarity. Nature, 421, 753-756. https://doi.org/10.1038/nature01423

[51] Nellika, R.K., Dharmapal, D., Sreeja, J.S. and John, R. (2019) $\alpha$-Fodrin Is Required for Organization of Functional Microtubules during Mitosis. Cell Cycle, 18, 2713-2726. https://doi.org/10.1080/15384101.2019.1656476

[52] Pattabiraman, D.R., Bierie, B., Kober, K.I., Thiru, P., Kraft, J.A., Zill, C., et al. (2016) Activation of PKA Leads to Mesenchymal-to-Epithelial Transition and Loss of Tumor-Initiating Ability. Science, 351, aad3680. https://doi.org/10.1126/science.aad3680

[53] Klymkowsky, M.W. and Savagner, P. (2009) Epithelial-Mesenchymal Transition-A Cancer Researcher's Conceptual Friend and Foe. The American Journal of Pathology, 174, 1588-1593. https://doi.org/10.2353/ajpath.2009.080545 
[54] Dunham, L.J. (1972) Cancer in Man at Site of Prior Benign Lesion of Skin or Mucous Membrane: A Review. Cancer Research, 32, 1359-1374.

[55] Deng, G., Lu, Y., Zlotnikov, G., Thor, A.D. and Smith, H.S. (1996) Loss of Heterozygosity in Normal Tissue Adjacent to Breast Carcinomas. Science, 274, 2057-2059. https://doi.org/10.1126/science.274.5295.2057

[56] Jemaa, M., Abdallah, S., Liedo, G., Perrot, G., Lesluyes, T., Teyssier, C., Roux, P., et al. (2017) Heterogeneity in Sarcoma Cell Lines Reveals Enhanced Motility of Tetraploid versus Diploid Cells. Oncotarget, 8, 16669-16689. https://doi.org/10.18632/oncotarget.14291

[57] Erenpreisa, J. and Crag, M.S. (2013) Three Steps to Immortality of Cancer Cells: Senescence, Polyploidy and Self-Renewal. Cancer Cell International, 13, Article No. 92. https://doi.org/10.1186/1475-2867-13-92

[58] Tse, H.T.K., Weaver, W.M. and Carlo, D.D. (2012) Increased Asymmetric and Multi-Daughter Cell Division in Mechanically Confined Microenvironments. PLoS ONE, 7, e38986. https://doi.org/10.1371/journal.pone.0038986

[59] Mirzayans, R., Andrais, B., Kumar, P. and Murray, D. (2016) The Growing Complexity of Cancer Cell Response to DNA-Damaging Agents: Caspase 3 Mediates Cell Death or Survival. International Journal of Molecular Sciences, 17, 708-723. https://doi.org/10.3390/ijms17050708

[60] Wang, Q., Wu, P.C., Dong, D.Z., Ivanova, I., Chu, E., Zeliadi, S., Vesselle, H. and Wu, D.Y. (2013) Polyploidy Road to Therapy-Induced Cellular Senescence and Escape. International Journal of Cancer, 132, 1505-1515. https://doi.org/10.1002/ijc.27810

[61] Roberson, R.S., Kussick, S.J., Vallieres, E., Chen, S.-Y.J. and Wu, D.Y. (2005) Escape from Therapy-Induced Accelerated Cellular Senescence in p53-Null Lung Cancer Cells and in Human Lung Cancers. Cancer Research, 65, 2795-2803. https://doi.org/10.1158/0008-5472.CAN-04-1270

[62] Sikora, E., Mosieniak, G. and Sliwinska, M.A. (2016) Morphological and Functional Characteristic of Senescent Cancer Cells. Current Drug Targets, 17, 377-387. https://doi.org/10.2174/1389450116666151019094724

[63] Puig, P.-E., Guilly, M.-N., Bouchot, A., Droin, N., Cathelin, D., Bouyer, F., Favier, L., Ghiringhelli, F., Kroemer, G., Solary, E., Martin, F. and Chauffert, B. (2008) Tumor Cells Can Escape DNA-Damaging Cisplatin through DNA Endoreduplication and Reversible Polyploidy. Cell Biology International, 32, 1031-1043. https://doi.org/10.1016/j.cellbi.2008.04.021

[64] Deberardinis, R.J. and Cheng, T. (2010) Q's Next: The Diverse Function of Glutamine in Metabolism, Cell Biology and Cancer. Oncogene, 29, 313-324. https://doi.org/10.1038/onc.2009.358

[65] Cantor, J.R. and Sabatini, D.M. (2012) Cancer Cell Metabolism: One Hallmark, Many Faces. Cancer Discovery, 2, 881-898. https://doi.org/10.1158/2159-8290.CD-12-0345

[66] Freed, J.J. and Schatz, S.A. (1969) Chromosome Aberrations in Cultured Cells Deprived of Single Essential Amino Acids. Experimental Cell Research, 55, 393-409. https://doi.org/10.1016/0014-4827(69)90574-6

[67] Cao, Y., Walen, K.H. and Schnurr, D. (1988) Coxsackievirus B-3 Selection of Virus Resistant Buffalo Green Monkey Kidney Cells and Chromosome Analysis of Parental and Resistant Cells. Archives of Virology, 101, 209-219.

https://doi.org/10.1007/BF01311002 
[68] Janssen, A. and Medena, R.H. (2011) Mitosis as an Anti-Cancer Target. Oncogene, 30, 2799-2809. https://doi.org/10.1038/onc.2011.30

[69] Murga, M., Jaco, I., Fan, Y., Soria, R., Martinez-Pastor, B., Cuadrado, M., et al. (2007) Global Chromatin Compaction Limits the Strength of the DNA Damage Response. Journal of Cell Biology, 178, 1101-1108. https://doi.org/10.1083/jcb.200704140

[70] Shih, I.-M., Zhou, W., Goodman, S.N., Lengauer, C., Kinzler, K.W. and Vogelstein, B. (2001) Evidence That Genetic Instability Occurs at an Early Stage of Colorectal Tumorigenesis. Cancer Research, 61, 818-822.

[71] Kaiser, J. (2018) Is Genome-Guided Cancer Treatment Hyped? Science, 360, 365. https://doi.org/10.1126/science.360.6387.365

[72] Stratton, M.R., Campbell, P.J. and Futreal, P.A. (2009) The Cancer Genome. Nature, 458, 719-724. https://doi.org/10.1038/nature07943

[73] Bignold, L.P., Coghlan, B.L.D. and Jersmann, H.P.A. (2007) David Paul von Hansemann: Contributions to Oncology. Context, Comments, and Translations. Birkhäuser Basel, Switzerland.

[74] Kaiser, J. (2012) Cancer Genetics with an Edge. Science, 337, 282-284. https://doi.org/10.1126/science.337.6092.282

[75] Garbe, J.C., Vrba, L., Sputova, K., Fuchs, L., Novak, P., Brothman, A.R., Jackson, M., et al. (2014) Immortalization of Normal Human Mammary Epithelial Cell in Two Steps by Direct Targeting of Senescence Barriers Does Not Require Gross Genomic Alterations. Cell Cycle, 13, 3423-3435.

https://doi.org/10.4161/15384101.2014.954456

[76] Amend, S.R., Torga, G., Lin, K.-C., Kosteca, L.G., de Marzo, A., Austin, R.H. and Plenta, K.J. (2019) Polyploid Giant Cancer Cells: Unrecognized Actuators of Tumorigenesis, Metastasis, and Resistance. The Prostate, 79, 1489-1497. https://doi.org/10.1002/pros.23877

[77] Jackson, S.P. and Helleday, T. (2016) Drugging DNA Repair. Science, 352, 1178-1179. https://doi.org/10.1126/science.aab0958

[78] Tomacetti, C., Li, L. and Vogelstein, B. (2017) Stem Cell Divisions, Somatic Mutations, Cancer Etiology, and Cancer Prevention. Science, 355, 1330-1334. https://doi.org/10.1126/science.aaf9011

[79] Nowak, M.A. and Waclaw, B. (2017) Genes, Environment, and "Bad Luck". Science, 355, 1266-1267. https://doi.org/10.1126/science.aam9746

[80] Adjiri, A. (2017) DNA Mutations May Not Be the Cause of Cancer. Oncology and Therapy, 5, 85-101. https://doi.org/10.1007/s40487-017-0047-1

[81] Hanahan, D. and Weinberg, R.A. (2011) Hallmarks of Cancer: The Next Generation. Cell, 144, 646-674. https://doi.org/10.1016/j.cell.2011.02.013

[82] Cairns, J. (1978) Cancer: Science and Society. W. H. Freeman and Company, USA.

[83] Raza, A. (2019) The First Cell: And the Human Costs of Pursuing Cancer to the Last. Hachette Book Group, New York.

[84] Clipponi, A., Goode, D.L., Bedo, J., McCabe, M.J., Pajic, M., Croucher, D.R., et al. (2020) MTOR Signaling Orchestrates Stress-Induced Mutagenesis, Facilitating Adaptive Evolution in Cancer. Science, 368, 1127-1131.

https://doi.org/10.1126/science.aau8768 